\title{
REINFORCED CONCRETE COLUMNS STRENGTHENED AT INTERSECTION WITH DROPPED BEAMS
}

\author{
Elsayed Ateya, Mohamad Alkersh \\ Department of Civil Engineering, Faculty of Engineering, Al-Azhar University, Cairo, Egypt. \\ E-mail: ElsayedAteya.14@azhar.edu.eg \\ E-mail: MohamadAlkersh.14@azhar.edu.eg
}

Received :25 Sept. $2021 \quad$ Accepted:16 Oct. 2021

\begin{abstract}
In the current high-rise reinforced concrete structures, high strength concrete is usually used for the columns, whereas normal strength concrete is usually used for ceilings (slabs and beams). In general, slabs and beams are cast constantly over the crossing zone of a beam-column. As a result, stress from the column above the beam must travel through a weaker beam concrete layer before reaching the column below the beam. The load-transmission mechanism through this sort of link is of significant importance and summarizes the whole behavior. However, theoretical studies that investigate the effective compressive strengths of the slab-column connection zone with dropped beams are still not yet available. In order to study compressive force of the column at the intersection, preliminary tests were carried out on five reinforced concrete specimens designed to simulate real column retention situation at the dropped beam and column intersection. The results show that concrete strength at the junction is increased by containment of the dropped beam system surrounding it. The sample demonstrated an increase in effective compressive strength as compared to that of the specimen without reinforcement with beam-column reinforced steel connection area.
\end{abstract}

Keywords: High-rise reinforced concrete buildings, Beam-column joint, Slab-column joint, Variable compressive strength, Confinement, Reinforced Concrete.

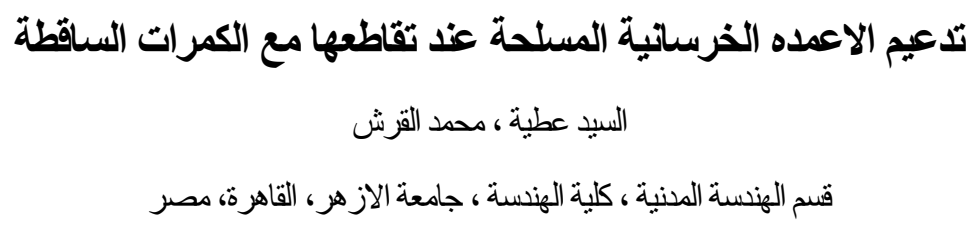

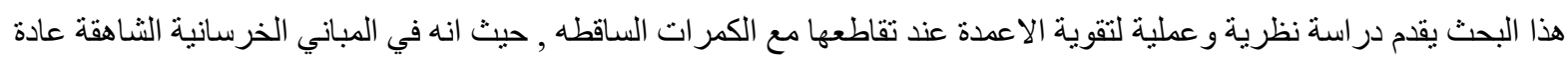

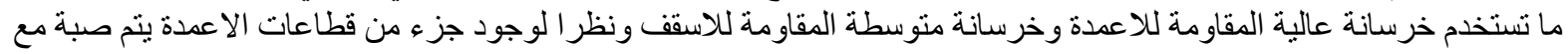
السقف وبناءا علية تنتقل قوة الضغط الموجوده في الاعمدة من خلال هذا الجزء حتي يصل الحمل الي قطاع العمود السفلي. تعتبر الية الية 


\section{DROPPED BEAMS}

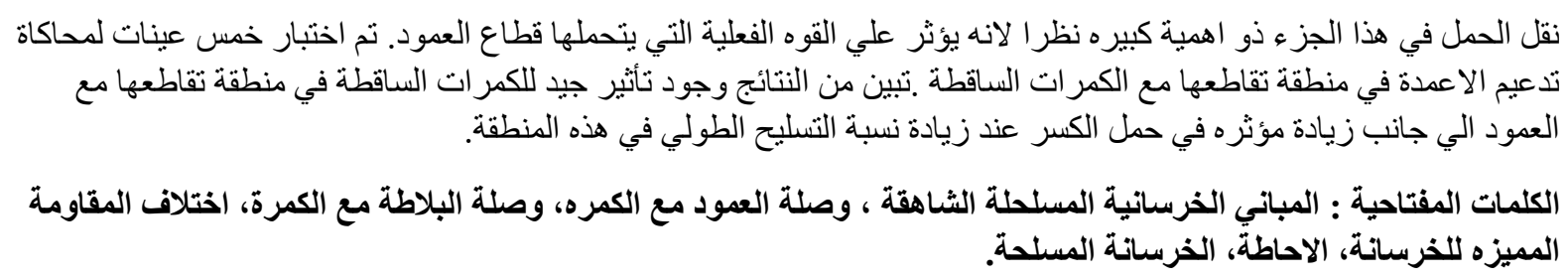

\section{INTRODUCTION}

Due to substantial development in the field of concrete technology, high strength is feasible in the production of concrete. High-strength concrete of $100 \mathrm{MPa}$ is applied especially in high-rise buildings.

The strong compressive resistance characteristics of concrete materials can be more effectively utilized in structural column members with the application of high-strength concrete (HSC). The usage of HSC allows columns to be reduced as well as concrete resources to be saved, which also allows effective floor areas. However, floors are preferred to be designed using normal strength concrete (NSC), because HSC is not economical to be applied to large floor slabs. While the column members are coated with HSC materials, they are also the same.

From an economic point of view, this approach is quite useful, but it makes it tough to connect to the floor slab. To optimize the utilization of material resistance characteristics, slabs are constructed of normal strength concrete or lightweight concrete aggregate. For this reason, significantly different strength characteristics of concrete come into contact. The effect of the crossing of high strength concrete by weaker slab concrete is thus seen as a serious concern.

When the column and floor slab members have different concrete compressive strength grades, the provisions on current design in ACI [2] require an acceptable load transmission at the slab-column junctions via one of the following three techniques;

The first technique is to construct a floor close to the position of the column using the same concrete strength as the concrete column, for which a concrete from the column must be poured up to $600 \mathrm{~mm}$ from the surface of the column before hardening column concrete according to ACI and KCI or $500 \mathrm{~mm}$ according to CSA [ref]. The concrete of the column is nicely incorporated with the concrete of the floor. For the column design, this approach is easy since the compressive strength of the concrete column may be used for the column design. However, it demands a high degree of monitoring, precise coordination of concrete deliveries and the probable use of retardants, which necessarily reduces buildability.

In the second technique, the column member's axial strength is calculated through the floor system based on a lower concrete strength value with vertical dowels and spirals as required.

The third technique suggests the effective compressive strength $\left(\mathrm{f}^{\prime}{ }_{\mathrm{ce}}\right)$ that will be used for the design of the member of the column. According to ACI and KCI, the column's compressive strength ( $\left.\mathrm{f}_{\mathrm{cc}}^{\prime}\right)$ is 1.4 times greater than that of the slabs in the compressive concrete slab $\left(\mathrm{f}^{\prime}{ }_{\mathrm{cj}}\right)$.

The current design codes (ACI 318-19; CSA A23.3-14 (2019)) include a provision where the load transmission performance is guaranteed by the column if the upper/lower columns and slabs have different compressive strengths, as shown in Figure (1-a) (Urban and Gołdyn 2015). The ACI 318-19 indicates that if the column concrete's compressive strength is 1.4 times greater than that of the slab's compressive strength, the column concrete should be either extended by more than $600 \mathrm{~mm}$ beyond the column face, as illustrated in Figure (1-b), be strengthened in Figure (1-c) with vertical dowels or spirals, or adopt the effective compressive strength ( $f^{\prime} \mathrm{ce}$ ).

Many models of regression, empirical mainly, for the prediction of the effective strength of the columnslab junction, based on mechanics of structures and materials [4, to 10]. ACI code [1] proposes that column strength ratios from column concrete to slab concrete strength up to 1.4 are not reduced for higher proportions, experiments based by Bianchini et al. [5], to forecast the effective strength of the joint, the following statement was suggested: 
DROPPED BEAMS

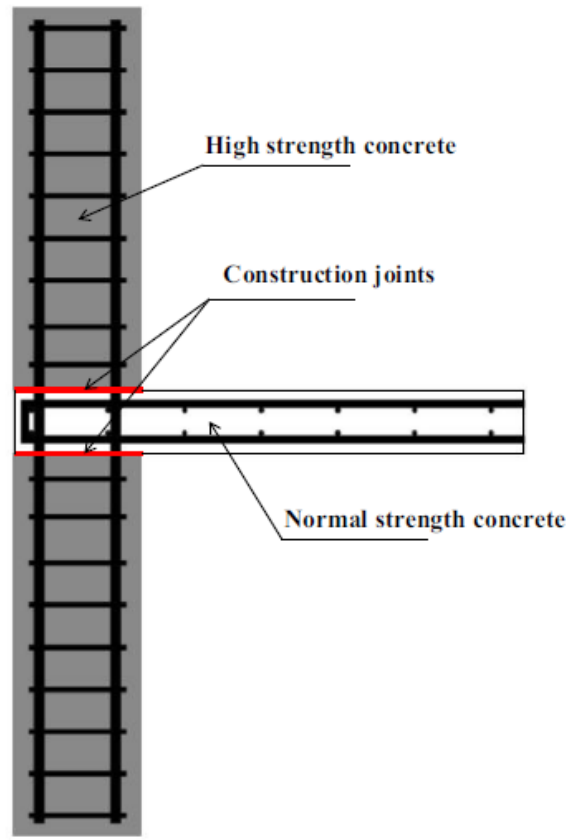

a Slab continuous through support zone

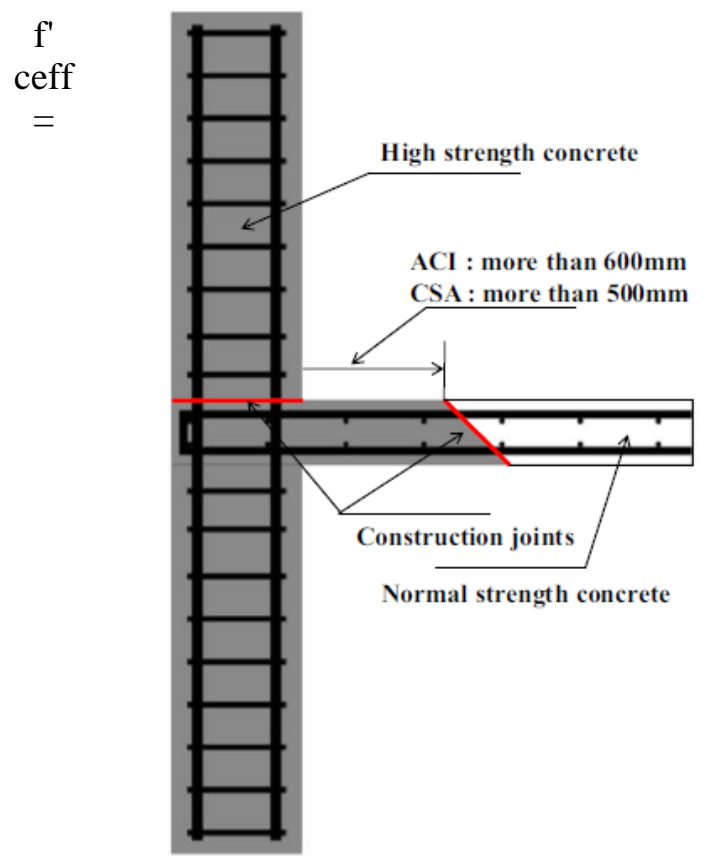

b Connection zone made of HSC

$0.75 f^{\prime}{ }_{c c}+0.35 f_{c s}^{\prime}$

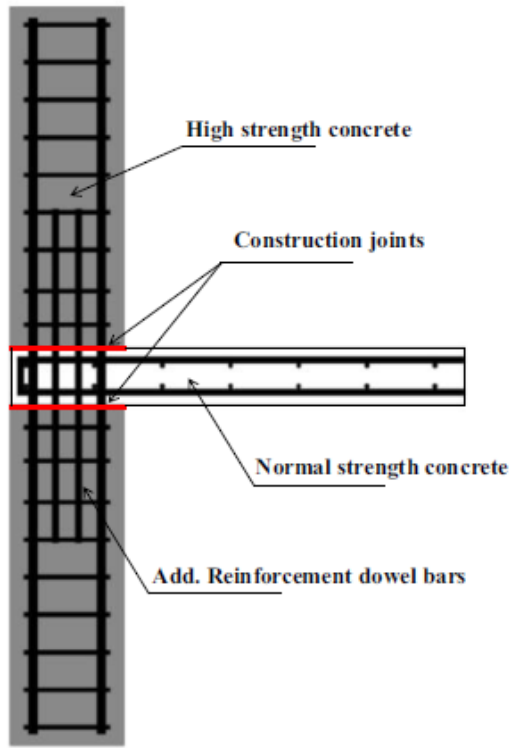

column-slab connection

c Additional longitudinal reinforcement

Where, $\mathrm{f}_{\mathrm{cc}}$ and $\mathrm{f}_{\mathrm{cs}}$ are respectively the column strength and slab concrete.

Gamble and Klinar [7] proposed the following for calculating the strength of a column-slab joint as a lower bound relationship:

$\mathrm{f}^{\prime}$ ceff $=0.47 \mathrm{f}_{\mathrm{cc}}^{\prime}+0.67 \mathrm{f}_{\mathrm{cs}}^{\prime}$

The ACI Code [2] equation has been reported to be adequate for column concrete strength to slab concrete strength ratio of 1.4. But with the larger ratios, design provisions ACI Code [2] overestimate and therefore insecure the effective strength of the joints.

The Canadian Standard CSA-A23.3:1994[6] provides the following design expression in current design standards covering high strength concrete for greater column concrete strength to concrete strength slab: 
$\mathrm{f}^{\prime}$ ceff $=0.25 \mathrm{f}_{\mathrm{cc}}^{\prime}+1.05 \mathrm{f}_{\mathrm{cs}}$

It seems safe to use, although extremely cautious, the effective strength prediction in CSA A23.3[6] design requirements.

The test programs of Bianchini et al. [5] are a noteworthy characteristic, and Gamble and Klinar [7] was the absence of slab load. In reality, in a building prototype, the load on the slab produces substantial tensile stress in the top flexural slab reinforcement near the column. The assumption that this strain would have a harmful impact on the capacity of the surrounding slab to restrict the column-slab junction would be reasonable [8]. The new design models have been created by Ospina and Alexander [8] that incorporated the influence of the slab thickness-column ratio (aspect ratio, $\mathrm{h} / \mathrm{c}$ ). The design equation, proposed to estimate the effective joint strength, is as follows:

$\mathrm{f}^{\prime}$ ceff $\left.=\overline{(\overline{h / c})}\right) \mathrm{f}_{\mathrm{cc}}^{\prime}+(1.4-\overline{k / c}) \mathrm{f}_{\mathrm{cs}}^{\prime}$

In addition to the strength of the columns and slabs and the aspect ratio $(\mathrm{h} / \mathrm{c})$, impacts of the slab confinement and slab strengthening ratio surrounding, rs, predicting the effective strength of the joint should also be considered [9]. Based on the new parameters induction, the following equation predicting has been drawn up:

$\mathrm{f}^{\prime}$ ceff $=0.35 \mathrm{f}_{\mathrm{cc}}+0.384\left(\frac{\rho s+4.12}{(h / c+1.47}\right) \lambda \mathrm{f}_{\mathrm{cs}}$

Recently, for the theoretical study of the problem, the mechanics of the material method, typically utilized for composite materials, have been adopted [10]. With the use of existing test data, this technique leads to a novel regression model for the effective strength calculation of the joint. Furthermore, the recent experiments [7, to 13] have tended to invalidate the limits ratio of 1.4 between the two concrete strengths, which ACI [1] allows in Sec. 10.15 of its construction code to be utilized without taking into account any unfavorable impacts on the column's axial load capability. The effective strength of the concrete joint has been determined to be commensurate with the product ratio and the total of the tworconcrete strengths as shown below:

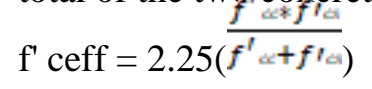

This discovery leads to a comparison between the behavior of the column specimens and that of composites materials. The gathered test data show that several mechanical principles of composite material are applicable to sandwiched concrete. In addition, it has been noted that several of the aforementioned models were built primarily for their own data by various scholars; except the Shah et al. model [9] utilized by a wide range of data.

\section{EXPERIMENTAL PROGRAM}

\subsection{Specimen Details}

A total of five specimens were manufactured with a cross-section column (120x170) mm, and (800) mm in length. The cross-section of beams in length (720) $\mathrm{mm}$ in the middle of the columns was (100x200) $\mathrm{mm}$. The heads of the columns on the top and the bottom (220x260) mm were given as shown in Figure (2). The columns' compressive strengths were shown as the upper and lowers columns' average strengths, because they had the same mixing design. The concrete mix was designed, aiming at a compressive strength of about $35 \mathrm{MPa}$ for the column and $24.2 \mathrm{MPa}$ for the beam after 28 days. For the columns, the vertical longitudinal reinforcement of all specimen was 4 bars with diameter $10 \mathrm{~mm}$ and the internal stirrups were $6 \mathrm{~mm}$ diameter bars at $100 \mathrm{~mm}$ spacing. For all beams, both the top and the bottom of the longitudinal reinforcement were two bars of $10 \mathrm{~mm}$ diameter and $6 \mathrm{~mm}$ diameter bar internal stirrups of $100 \mathrm{~mm}$ spacing. The control specimen $\mathrm{C} 0$ in Figure (3) has no additional reinforcement. (C1-1\&C1-2) contain extra internal stirrups in joint interaction between column-beam their number $(1 \& 2)$ respectively with $6 \mathrm{~mm}$ diameter bars and $(\mathrm{C} 2-1 \& \mathrm{C} 2-2)$ have additional vertical 
longitudinal reinforcement. Their number $(2 \& 4)$ respectively were $12 \mathrm{~mm}$ diameter bars. The specific parameter of each specimen is described in Table (1).
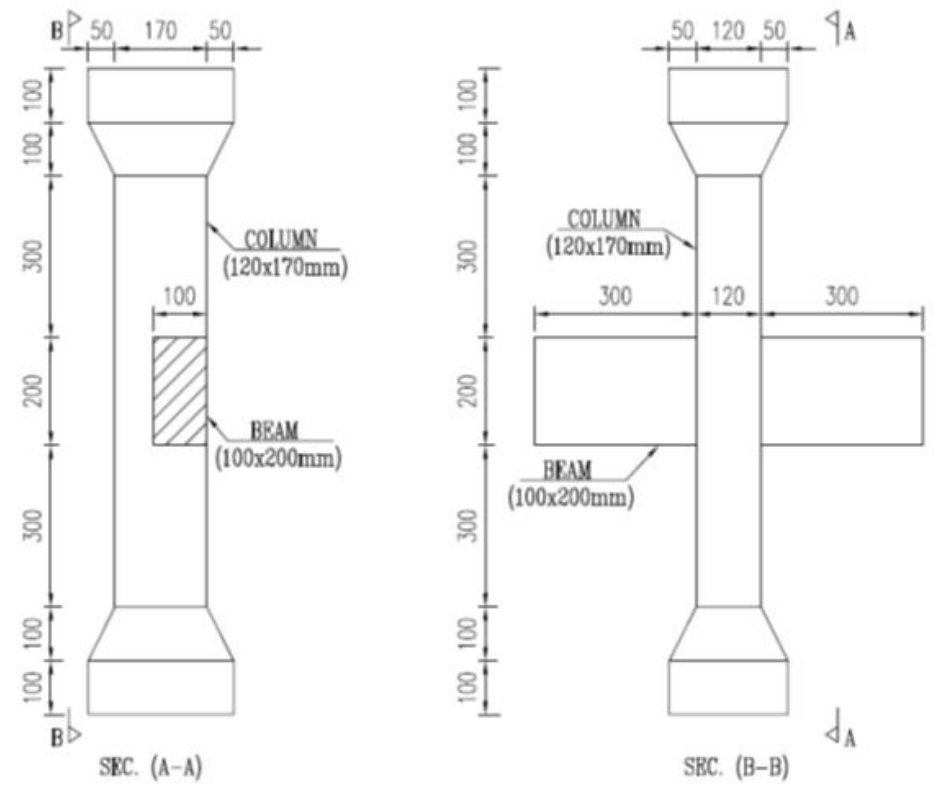

Figure 2 specimens' concrete dimension

Table 1 Specific parameter of each column

\begin{tabular}{|c|c|c|c|c|c|}
\hline Group & Column & $\begin{array}{c}\text { Columns' } \\
\text { compressive } \\
\text { strengths } \\
(\mathrm{MPa})\end{array}$ & $\begin{array}{c}\text { Beams } \\
\text { compressive } \\
\text { strengths } \\
\text { (MPa) }\end{array}$ & $\begin{array}{c}\text { additional } \\
\text { vertical } \\
\text { reinforcement }\end{array}$ & $\begin{array}{c}\text { additional } \\
\text { internal } \\
\text { stirrups }\end{array}$ \\
\hline reference & C-0 & 35 & 24.2 & ----- & ---- \\
\hline \multirow{2}{*}{1} & C 1-1 & 35 & 24.2 & ----- & 1 Ø 6 \\
\cline { 2 - 6 } & C 1-2 & 35 & 24.2 & ----- & $2 \emptyset 6$ \\
\hline \multirow{2}{*}{2} & C 2-1 & 35 & 24.2 & $2 \varnothing 12$ & ----- \\
\cline { 2 - 6 } & C 2-2 & 35 & 24.2 & $4 \varnothing 12$ & ---- \\
\hline
\end{tabular}

The test specimens were divided into two groups and a column reference depending on additional vertical reinforcement or internal stirrups as shown in Figure (3). 

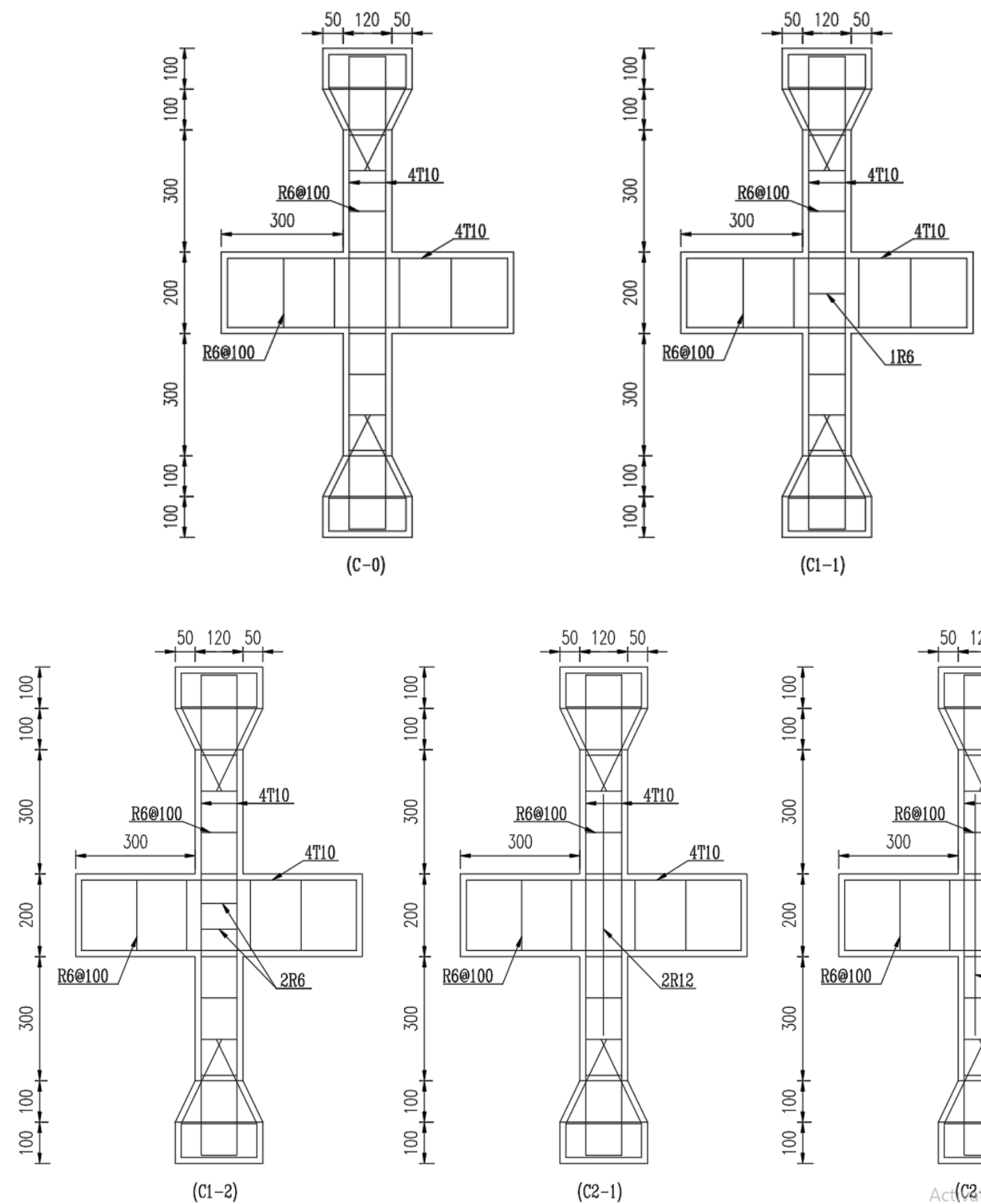

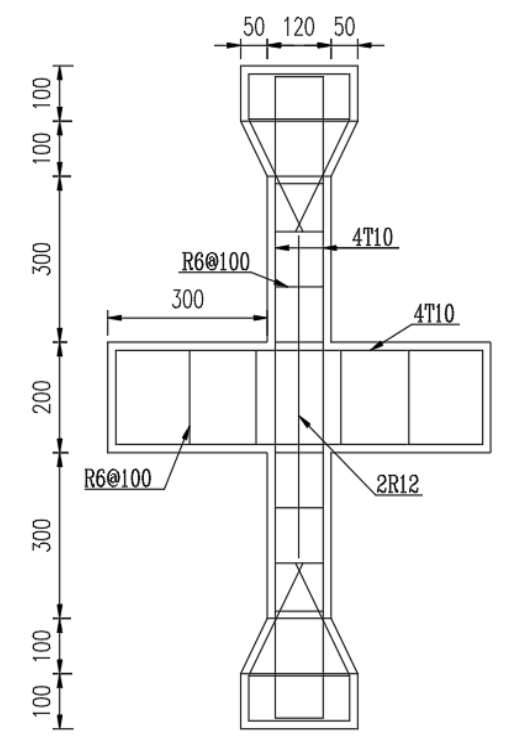

(C2-1)

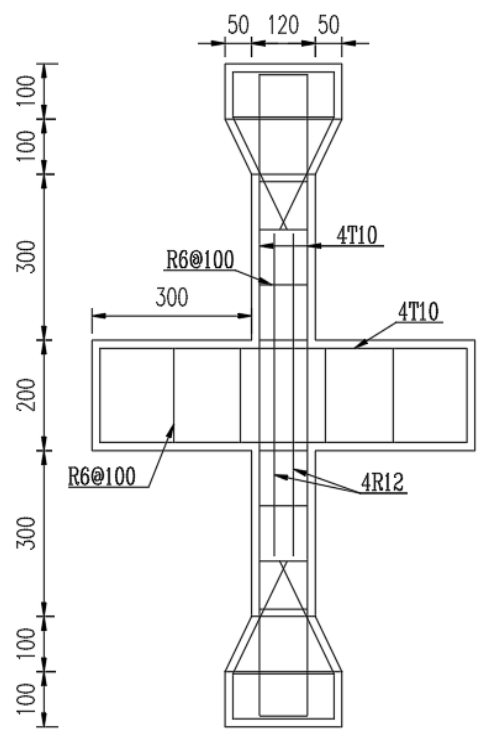

Ac (C2 +2$)$ Vindows

Figure 3 Details of reinforcement for all columns

\subsection{Test Setup}

The structural-testing machine in the Reinforced Concrete Laboratory at the Civil Engineering Department of Al-Azhar University was used to test. One hydraulic jack was used with capacity 100 Ton. Horizontal displacement at mid-point of columns was measured using LVDT, while strains of inner longitudinal reinforcement and strains of external stirrups were also observed. The vertical loads were measured at different stages of loading. The test setup is shown in Figure (4). 


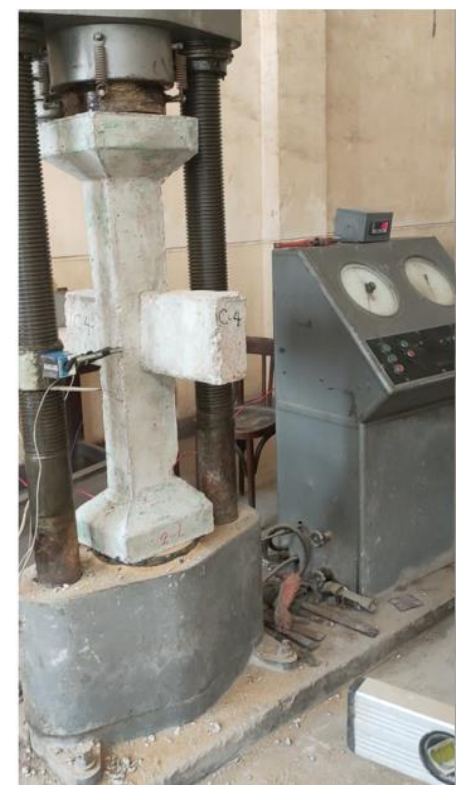

Figure 4: Test Setup

\section{RESULTS AND DISCUSSION}

The following observations have been concluded about the behavior of the columns tested:

\subsection{Failure Loads}

The failure loads of the tested columns were compared with estimated failure loads due to failure according to the American Code (ACI -440) [1] and the Egyptian Code (ECP-208) [2]. The failure mode in all specimens occurs in the beam column joint zone as shown in Figure (5). The experimental failure loads of group 1 and group 2 are shown in Figures (6\&7) respectively. From the previous figures, it can be concluded that the additional longitudinal steel has more effect than additional confinement of beam column joint.
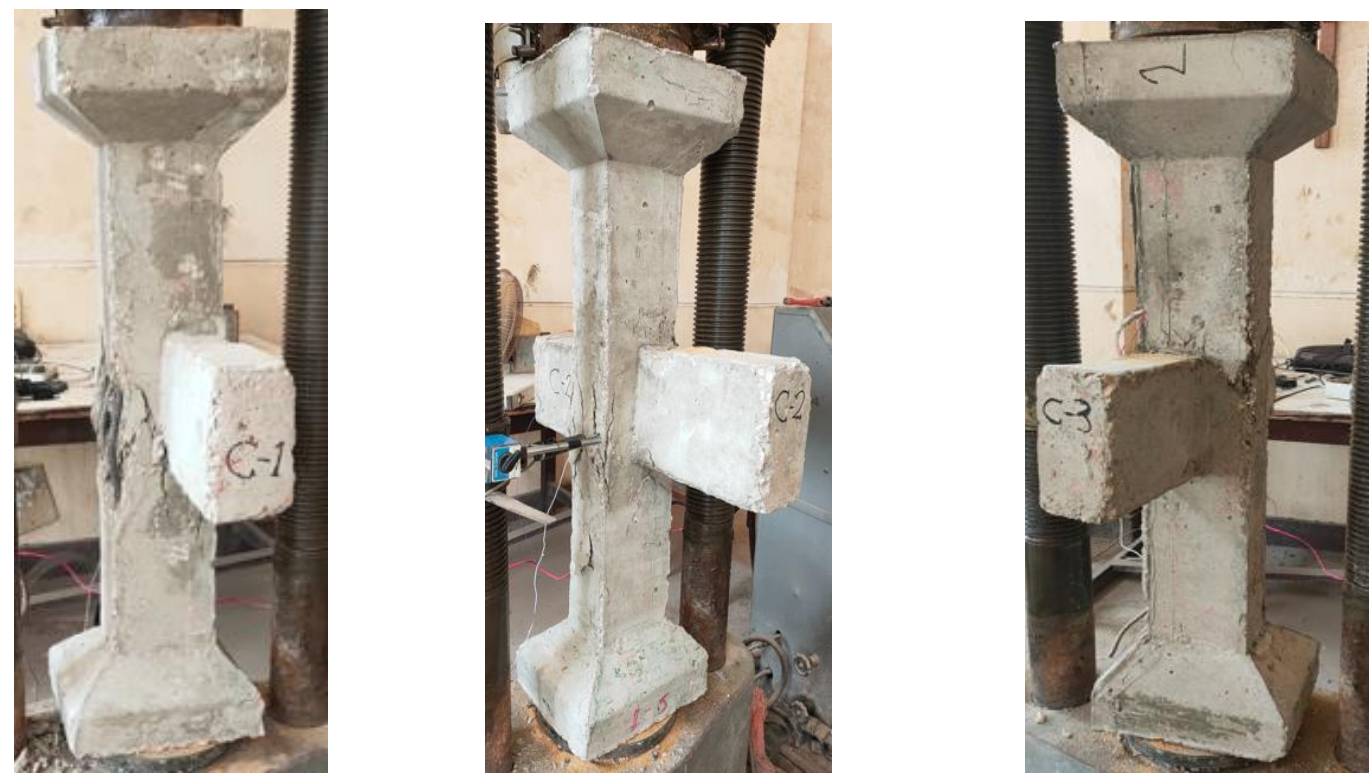

Figure 5 Cracks Pattern of Group 1 (C1-1\&C1-2) 


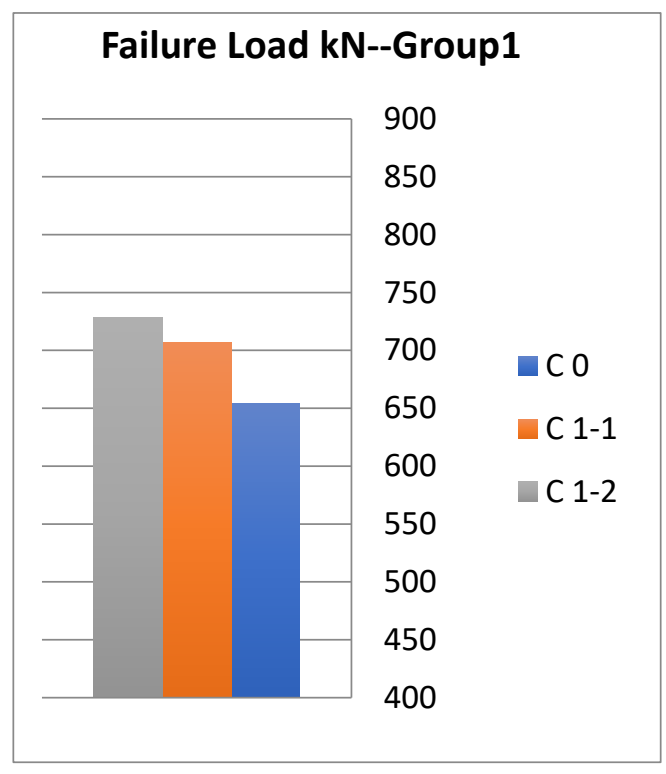

Figure 6: Failure Loads for Group (1)

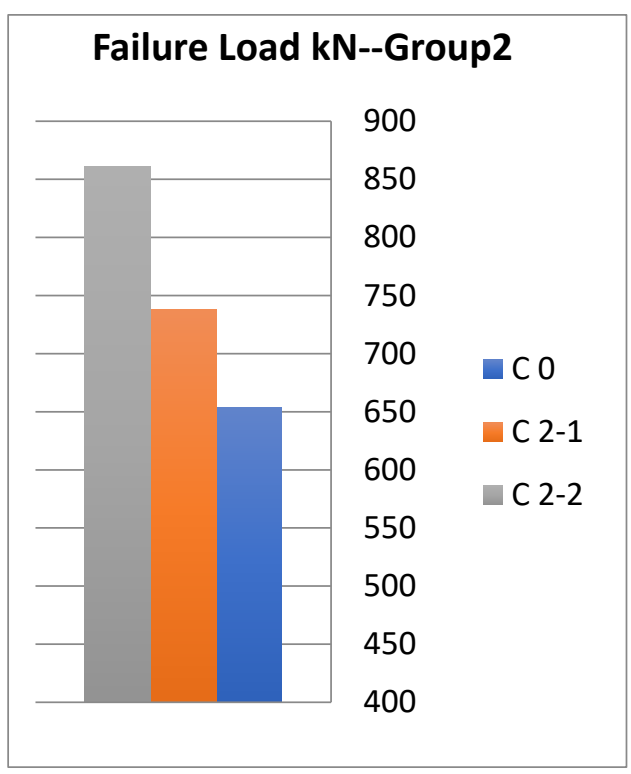

Figure 7: Failure Loads for Group (2)

\subsection{Steel Strains}

The longitudinal steel strains were obtained from the electrical strain gauges. Figures (8) and (9) show the load and longitudinal steel strain curves through the load history for group 1 and group 2 respectively.

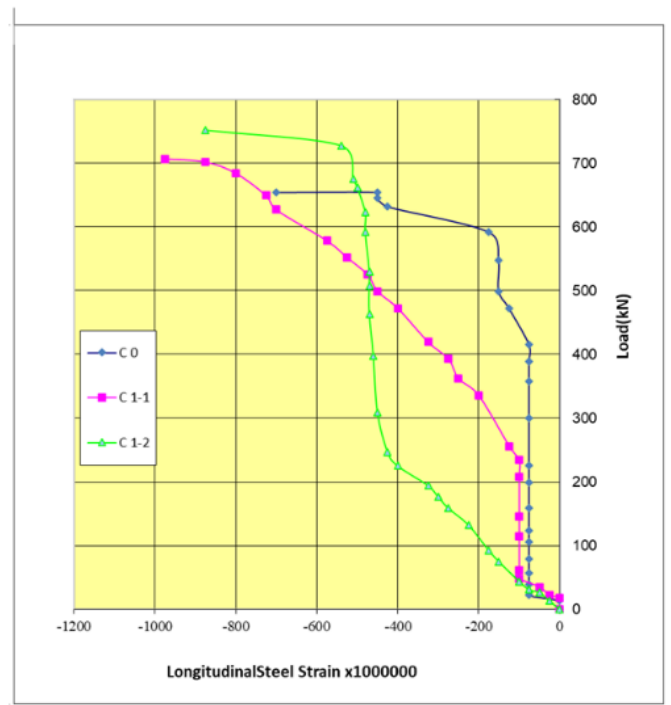

Figure 8: Load-Steel Strain Curves for Group (1)

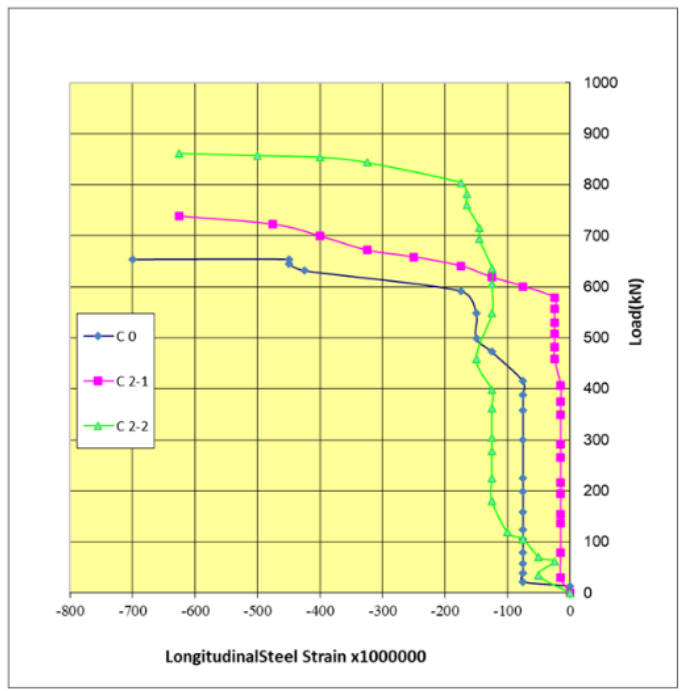

Figure 9: Load-Steel Strain Curves for Group (2)

\subsection{Discussion of Results}

The experimental results showed the efficiency of the confinement of the specimen. The increase in column capacities ranged from $8 \%$ to $15 \%$ in Group (1), and from $13 \%$ to $30 \%$ in Group (2). It was observed that the specimen with additional longitudinal steel showed higher increase in column capacities than specimen with confinement of beam column zone. 


\section{ANALYTICAL MODELS}

The specimens were modeled using finite element analysis. The used software was ABAQUS 6.12. The analysis was based on the non-linear iterative secant stiffness formulation. For compressive and tensile behavior, Concrete Damaged Plasticity model was used to describe the yield criterion of concrete as compressive behavior and tension behavior as shown in Figures (10) and (11). The stress strain curve of reinforcement was plotted as bilinear behavior. Damaged Plasticity model was used to describe the yield criterion of concrete.

The stress strain curve of reinforcement was plotted as shown in Figure (12).

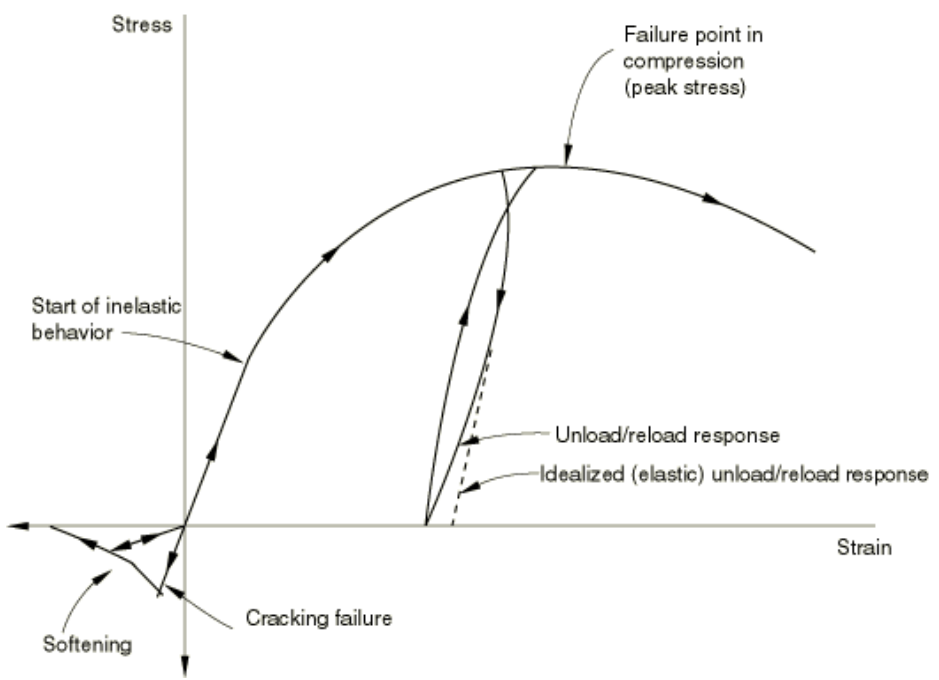

Figure 10: Axial behavior of plain concrete

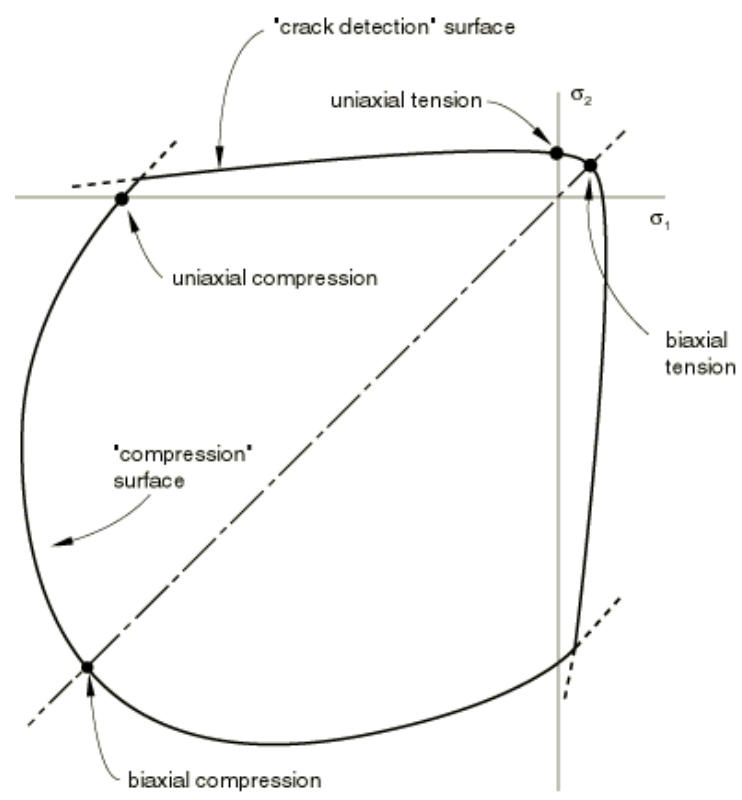

Figure 11: Concrete failure surfaces in plane stress. 


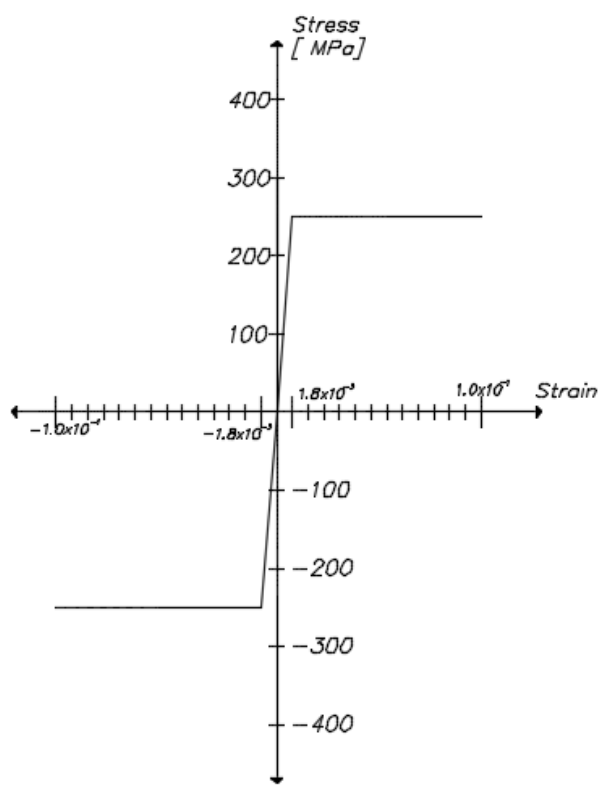

Figure 12: Idealized stress strain curve of reinforcement

The simulation of column $\mathrm{C} 0$ is shown in Figure (13). The failure was considered in the theoretical results when the stress in concrete began to decrease after that the strain in concrete began to reach 0.003 . The difference between experimental and theoretical results was less than $8 \%$.

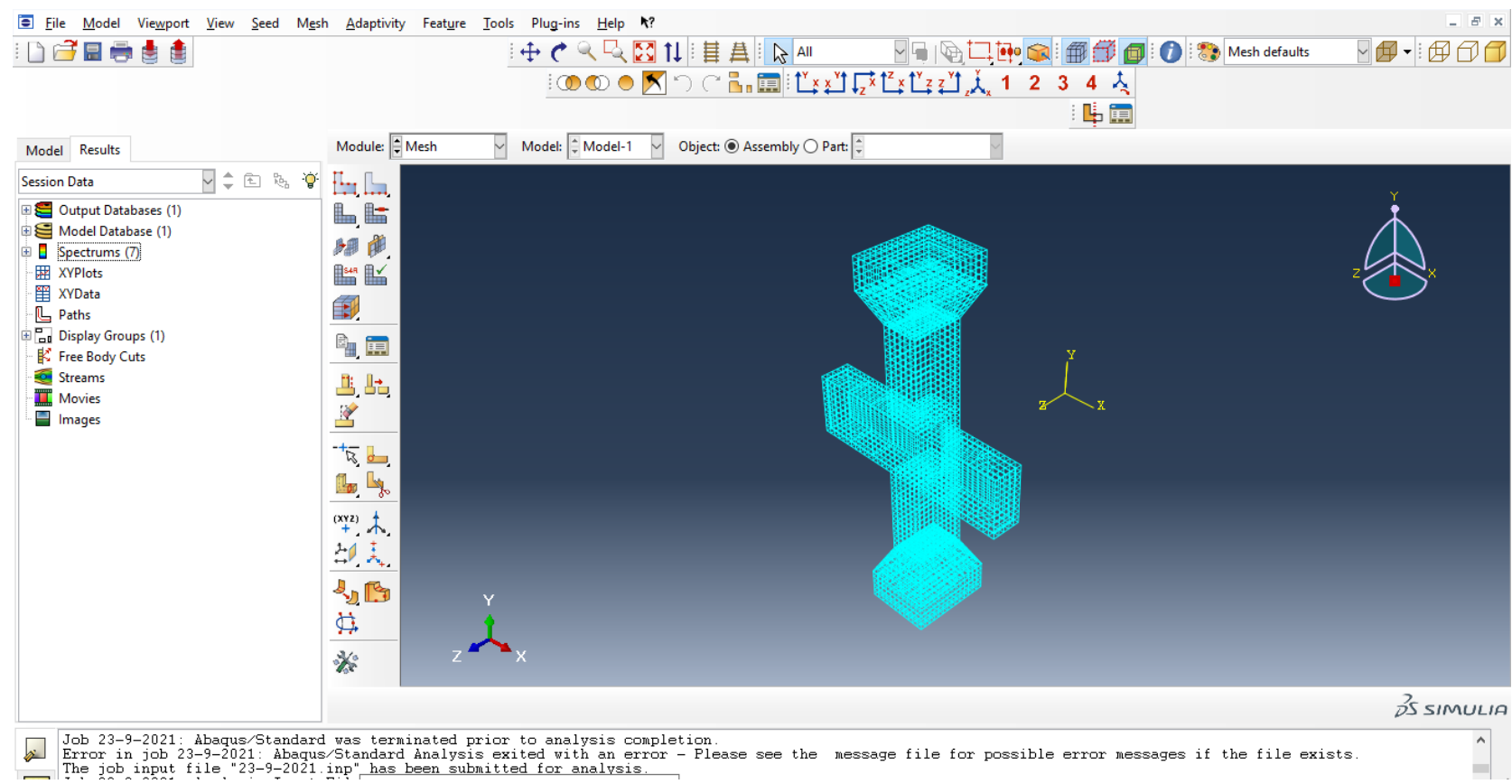

Figure 13: simulation of Column C 0

\section{SUMMARY AND CONCLUSIONS}

The present study investigated the effect of additional longitudinal steel and the confinement of beam column joint using internal steel stirrups. The following summarizes the findings of this investigation: 
1. A successful method for increasing the capacity of beam column joint by using additional longitudinal steel bars.

2. Additional longitudinal steel bars in beam column joint showed an increase of about $15 \%$ in column capacity.

3. A successful method for increasing the capacity of beam column joint by using additional steel stirrups which made a confinement zone of concrete which has lowest strength.

4. Additional steel stirrups in beam column joint showed an increase of about $30 \%$ in column capacity.

5. Finite element models showed good agreement with the experimental results in the capacities and strain result. The difference between the experimental and theoretical results ranged between $5 \%$ to $8 \%$.

\section{REFERENCES}

1. ACI 228.2R-13 (2013), "Nondestructive test methods for evaluation of concrete in structures", American Concrete Institute Report, Farmington Hills, U.S.A.

2. ACI Committee 318 (2014), Building Code Requirements for Structural Concrete and Commentary, American Concrete Institute.

3. Urban, T.S., and Gołdyn, M.M. (2015), "Behaviour of Eccentrically Loaded High-Strength Concrete Columns Intersected by Lower-Strength Concrete Slabs", Struct. Concr., 16(4), 480495.

4. A. C. Bianchini, R. E. Woods, and C. E. Kesler. Effect of floor concrete strength on column strength. ACI Journal, 31(11):1149-69, 1960.

5. Canadian Standards Association (CSA A23.3-94), Rexdale, Ontario, Canada. Design of concrete structures, 1994.

6. W. L. Gamble and J. D. Klinar. Tests of high-strength concrete columns with intervening floor slabs. ASCE Journal of Structural Engineering, 117(5):1462-76, 1991.

7. C. E. Ospina and S. D. B. Alexander. Transmission of interior concrete column loads through floors. ASCE Journal of Structural Engineering, 124(6):602-10, 1998.

8. A. A. Shah, J. Dietz, N. V. Tue, and G. Koenig. Experimental investigation of column-slab joints. ACI Struct J, 102(1):103-13, 2005.

9. A. A. Shah and Y. Ribakov. Using mechanics of materials approach for calculating interior slabcolumn joints strength. Materials and Design, 29(8):1145-1158, 2008.

10. F. Jungwirth. Knotenpunkt: normalfeste Decke-hochfeste Ortbetonstutze. Leipzig annual journal on concrete and concrete structures, 3(1):165-74, 1998. Leipzig Annual Civil Engineering Report [in German].

11. P. J. McHarg, W. D. Cook, D. Mitchell, and Y. S. Yoon. Improved transmission of high strength concrete column loads through normal strength concrete slabs. ACI Structural Journal, 97(1):157-66, 2000.

12. A. A. Shah and Y. Ribakov. Experimental and analytical study of flat-plate floors confinement. Materials and Design, 26(8):655-69, 2005. 